\title{
From genetics to prognosis
}

\author{
Can Yerebakan, MD, and Manan Desai, MD
}

\footnotetext{
From the Division of Cardiovascular Surgery, Children's National Heart Institute, Children's National Health System, The George Washington University School of Medicine, Washington, DC

Disclosures: Authors have nothing to disclose with regard to commercial support.

Received for publication March 10, 2018; accepted for publication March 19, 2018; available ahead of print April 14, 2018.

Address for reprints: Can Yerebakan, MD, Cardiovascular Surgery, Children's National Heart Institute, Children's National Health System, The George Washington University School of Medicine, 111 Michigan Ave NW, Washington, DC 20010 (E-mail: cyerebakan@childrensnational.org).

J Thorac Cardiovasc Surg 2018;156:775-6

$0022-5223 / \$ 36.00$

Copyright (C) 2018 by The American Association for Thoracic Surgery

https://doi.org/10.1016/j.jtcvs.2018.03.067
}

Cardiomyopathies in childhood are challenging cardiac disorders that carry high mortalities. Cardiac transplantation is the treatment of choice in case of intractable cardiac failure; however, the chronic shortage of donor organs hinders its unlimited application. Medical and surgical management strategies evolve steadily to improve the outcomes of our patients. Better risk stratification and novel alternatives for medical and surgical treatment options are therefore required. ${ }^{1,2}$

Left ventricular noncompaction (LVNC) is an entity with still debatable classification. It has been classified as a distinct cardiomyopathy but also as a subtrait of other major cardiomyopathies. $^{3,4}$ The definition differs in the guidelines of various medical societies, so the true incidence is unclear. It has been reported to affect the pediatric population the most after dilated cardiomyopathy and hypertrophic cardiomyopathy. ${ }^{5}$ LVNC has increasingly been diagnosed in adults presenting in the echocardiographic laboratory. ${ }^{6}$ LVNC shares many of its genetic mutations with sarcomere genes. Familial inheritance as a genetic disorder has been reported in many series. One of the most common mutations occur in $M Y H 7$, the $\beta$-myosin heavy chain gene. ${ }^{7,8} C D 36$ mutation, on the other hand, has been known to cause a wide variety of pathologic manifestations, from atherosclerosis to hypertrophic cardiomyopathy.

In the March 2018 issue of the Journal, Hirono and colleagues ${ }^{10}$ describe the presence of 2 simultaneous variant of MYH7 and CD36 genes in a prenatally diagnosed case of LVNC and discusses its impact on the prognosis. Hirono and colleagues ${ }^{10}$ are to be congratulated on the prenatal detection of the cardiomyopathy and the coexistence of both gene variants with cardiac phenotype in the same patient. A recent retrospective study from the Netherlands in 327 patients at 4 centers showed that those with LVNCrelated genes with known mutations were more likely to have cardiac symptoms, left ventricular systolic dysfunction, and high risk of major cardiac adverse events. ${ }^{8}$ Probst and associates, ${ }^{11}$ however, discussed that sarcomere mutations per se did not predict clinical phenotype.
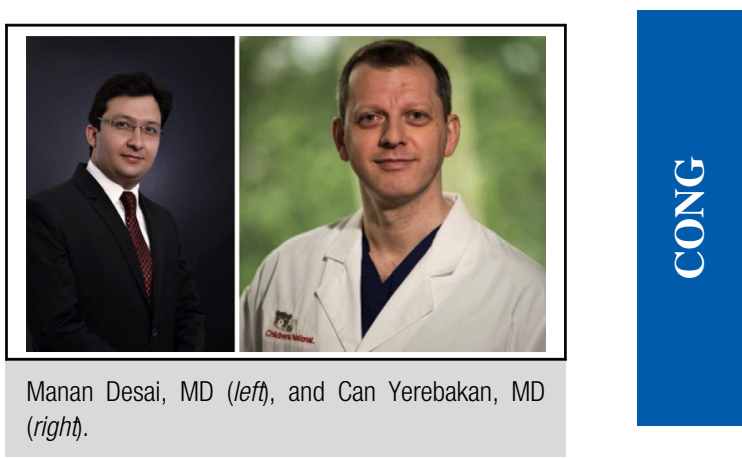

Central Message

We are moving from early prenatal detection of cardiac diseases to an understanding of the underlying genetic disorders. Their early treatment in the prenatal period may be the future.

See Article page e101 in the March 2018 issue.

Whether the coexistence of the 2 described mutations in the same patient explain prolonged pleural effusions, pericardial effusions, and ascites remains debatable. The patient underwent pulmonary artery banding and continuous prostaglandin infusion as part of a hybrid stage I palliation. We need to know more details of the surgical and postoperative medical approach to be able to attribute the clinical course fully to the rare coexistence of the mutations. Abnormal long-chain fatty acid metabolism is observed in myocytes with CD36 deficiency. ${ }^{12}$ Even when the clinical significance is not clarified in the mentioned study, the described patient may be tested for this disorder.

A prenatal detection and genetic follow-up of a cardiac disease by clarifying underlying mutations already indicates the future objectives of modern medicine, which are early detection of cardiac diseases and offering potential prenatal medical, surgical, or genetic treatment options. Accurate counseling of parents for the postnatal period in light of the clinical and genetic information may become possible early in the pregnancy. For surgeons, such information with prognostic significance may play an extremely important role in the timing and selection of different available surgical strategies. Continuous efforts to achieve this goal should therefore be strongly encouraged.

\section{References} 1. Latus H, Yerebakan C, Akintuerk H, Schranz D. Transcatheter interatrial com-
munications for the treatment of left heart disease: application in the pediatric
population. J Heart Lung Transplant. 2016;35:1274-5. 
2. Latus H, Hachmann P, Gummel K, Recla S, Voges I, Mueller M, et al. Biventricular response to pulmonary artery banding in children with dilated cardiomyopathy. J Heart Lung Transplant. 2016;35:934-8.

3. Elliott P, Andersson B, Arbustini E, Bilinska Z, Cecchi F, Charron P, et al. Classification of the cardiomyopathies: a position statement from the European Society of Cardiology Working Group on myocardial and pericardial diseases. Eur Heart J. 2007;29:270-6.

4. Maron BJ, Towbin JA, Thiene G, Antzelevitch C, Corrado D, Arnett D, et al; American Heart Association; Council on Clinical Cardiology, Heart Failure and Transplantation Committee; Quality of Care and Outcomes Research and Functional Genomics and Translational Biology Interdisciplinary Working Groups; Council on Epidemiology and Prevention. Contemporary definitions and classification of the cardiomyopathies: an American Heart Association scientific statement from the Council on Clinical Cardiology, Heart Failure and Transplantation Committee; Quality of Care and Outcomes Research and Functional Genomics and Translational Biology Interdisciplinary Working Groups; and Council on Epidemiology and Prevention. Circulation. 2006;113:1807-16.

5. Nugent AW, Daubeney PE, Chondros P, Carlin JB, Cheung M, Wilkinson LC, et al; National Australian Childhood Cardiomyopathy Study. The epidemiology of childhood cardiomyopathy in Australia. N Engl J Med. 2003;348:1639-46.

6. Sandhu R, Finkelhor RS, Gunawardena DR, Bahler RC. Prevalence and characteristics of left ventricular noncompaction in a community hospital cohort of patients with systolic dysfunction. Echocardiography. 2008;25:8-12.
7. Hoedemaekers YM, Caliskan K, Michels M, Frohn-Mulder I, van der Smagt JJ, Phefferkorn JE, et al. The importance of genetic counseling, DNA diagnostics, and cardiologic family screening in left ventricular noncompaction cardiomyopathy. Circ Cardiovasc Genet. 2010;3:232-9.

8. van Waning JI, Caliskan K, Hoedemaekers YM, van Spaendonck-Zwarts KY, Baas AF, Boekholdt SM, et al. Genetics, clinical features, and long-term outcome of noncompaction cardiomyopathy. J Am Coll Cardiol. 2018;71: 711-22.

9. Hirano K, Kuwasako T, Nakagawa-Toyama Y, Janabi M, Yamashita S, Matsuzawa Y. Pathophysiology of human genetic CD36 deficiency. Trends Cardiovasc Med. 2003;13:136-41.

10. Hirono K, Sakai T, Hata Y, Nishida N. The presence of multiple variants affects the clinical phenotype and prognosis in left ventricular noncompaction after surgery. J Thorac Cardiovasc Surg. 2018;155:e110-9.

11. Probst S, Oechslin E, Schuler P, Greutmann M, Boyé P, Knirsch W, et al. Sarcomere gene mutations in isolated left ventricular noncompaction cardiomyopathy do not predict clinical phenotype. Circ Cardiovasc Genet. 2011;4: 367-74.

12. Nozaki S, Tanaka T, Yamashita S, Sohmiya K, Yoshizumi T, Okamoto F, et al. CD36 mediates long-chain fatty acid transport in human myocardium: complete myocardial accumulation defect of radiolabeled long-chain fatty acid analog in subjects with CD36 deficiency. Mol Cell Biochem. 1999;192: $129-35$. 